\title{
Environmental impacts of household goods in Europe: a process-based life cycle assessment model to assess consumption footprint
}

\author{
Valentina Castellani ${ }^{1} \cdot$ Esther Sanyé-Mengual $^{1}$ - Serenella Sala ${ }^{1}$ (i)
}

Received: 10 February 2021 / Accepted: 29 September 2021 / Published online: 25 October 2021

(c) The Author(s) 2021

\begin{abstract}
Purpose Current patterns of household goods consumption generate relevant environmental pressures and impacts. Environmental impacts are not only limited to the European territory but also to third countries from where products are imported. Assessing the entire life cycle of products enables considering trade-related transboundary effects along supply chains. The goal of this paper is to illustrate the assessment of the environmental impacts of household goods consumption in Europe, modelled through the consumption footprint indicator.

Methods The consumption footprint indicator was designed to assess the environmental impact of household consumption by covering five areas of consumption (food, mobility, housing, household goods and appliances), each of them modelled as a basket of products $(\mathrm{BoP})$ representing the most consumed products by EU citizens. This paper focuses on the BoP household goods, entailing a large variety of products from clothes to personal care products. Consumption intensity was obtained from consumption statistical data for years 2010 and 2015. Life cycle inventory data for 30 representative products were obtained from EU Ecolabel background reports, screening reports of the Product Environmental Footprint pilots and literature. The 16 impact categories of the Environmental Footprint 3.0 method were employed for the impact assessment. Results and discussion Main impacts generated by household goods in EU (calculated after normalization and weighting) were on climate change, fossil resource use and water use. Components' manufacture was the most impacting stage for several impact categories. Paper products, detergents, furniture and clothes were the product groups contributing the most due to a combination of consumption intensity and environmental profile of products. Environmental impacts due to household goods consumption were higher in 2015 than in 2010.

Conclusions The impacts of EU household goods consumption are driven by both consumption intensity and the environmental impact profile of products. Therefore, sustainable actions should focus not only on the environmental profile of products, but also on consumer choices and behaviours.

Recommendations The BoP household goods model can be used as a baseline to assess the effect of consumer choices, by creating and comparing consumers' profiles that differ in the composition of the BoP and in the apparent consumption (defined as Production-Exports + Imports). The availability of detailed inventories for all the life cycle phases allows for modelling scenarios to assess the potential effect of innovations in the production phase and of the choice of alternative raw materials and ingredients.
\end{abstract}

Keywords Household consumption $\cdot$ SDG12 Environmental footprint $\cdot$ Consumption footprint $\cdot$ Life cycle thinking

Communicated by Guido W. Sonnemann

Serenella Sala

serenella.sala@ec.europa.eu

Valentina Castellani

castellani.valentina@gmail.com

1 European Commission - Joint Research Centre, Via E. Fermi 2749, 21027 Ispra, Italy

\section{Introduction}

Current European consumption patterns generate relevant environmental pressures and impacts, as highlighted by the State of the European Environment (SOER) (EEA 2019), including not only those related to greenhouse gas emissions but also natural resource use and other emissions to the environment. Such pressures are originated along the life 
cycle of products and services, beyond their use. Furthermore, the share of imports of consumer goods to Europe is increasing (Corrado et al. 2019; Eurostat 2019a), with embedded environmental impacts taking place beyond the EU territory due to European consumption patterns. Besides, importing products from countries with environmental laws weaker than the EU ones may lead to final products with larger embedded environmental impacts compared to domestic EU ones (Liobikiene and Dagiliute 2016; Sanyé-Mengual et al. 2019). Consequently, EU environmental policies have gradually changed the focus from cleaner production, through sustainable products, to a more holistic approach for sustainable consumption and production, e.g. considering the selection of raw materials or ingredients with a lower environmental impact along their life cycle, reducing direct impacts related to the use phase of products (e.g. electricity use) and raising awareness on the effect of lifestyles and consumption intensity. The European Green Deal (EC 2019) and associated strategies and plans, the Farm to Fork strategy (EC 2020a), the Biodiversity Strategy (EC 2020b) and the new Circular Economy Action Plan (EC 2020c), highlight the need to shift towards a more sustainable EU production and consumption considering the entire supply chain of products and the transboundary effects on other countries. Such efforts are aligned to Sustainable Development Goal (SDG) 12 (UN 2015), which aims at responsible production and consumption.

Specific hotspots can be identified for different types of household products. For instance, absorbent products have been largely identified as a relevant source of impact, particularly due to their noteworthy volume share of municipal solid waste (Arena et al. 2016; Cordella et al. 2015). Cosmetics and pharmaceutical products are associated to a relevant impact on the aquatic environment after their use, if their components are released into municipal wastewater (Ternes et al. 2004).

The presence of chemicals in consumer products is also a known environmental hotspot, since they may become sources of chemical emissions with a diverse spectrum of health effects, e.g. endocrine disruption or associations with asthma (Dodson et al. 2012; Kabir et al. 2015). Literature suggests that phthalates, alkylphenols, parabens, polychlorinated biphenyls (PCBs) and polybrominated diphenyl ether (PBDE) flame retardants in households can originate from consumer goods (e.g. Rudel et al. 2003). However, further research in this field is needed, particularly due to the large range of products and compounds potentially released. Chemicals in 100 consumer products including formulations (e.g. shampoos, paints), articles (e.g. upholsteries, shower curtains) and foods (cereals) were characterized towards supporting chemical prioritization based on potential human health risks (Phillips et al. 2018). Vojta et al. (2017) analysed 137 individual samples of consumer products, building materials and waste, for identifying and characterizing potential sources of halogenated flame retardants (e.g. upholstered furniture) in indoor environment. A life cycle assessment (LCA) study of 15 nanosilver-enabled consumer products unveils that the release of silver nanoparticles employed to neutralize odour in textiles and food containers have direct ecotoxicity impacts in products with high leaching rates, surpassing the cradle-to-gate impacts (Pourzahedi et al. 2017).

A growing number of studies quantifying the environmental impacts of the overall consumption and use of household goods taking a life cycle perspective have been published, employing both process-based LCA (e.g. Kalbar et al. 2016, for Denmark; Teubler et al. 2018, on the embodied resource use of household goods in Germany) and input-output-based LCA (e.g. Duarte et al. 2010; Zhu et al. 2012; Ivanova et al. 2016; Wood et al. 2017). In particular, Ivanova et al. (2016) assessed the contribution of several household consumption categories (i.e. food, mobility, housing, clothing and footwear, manufactured products and services) to the direct and embodied environmental impacts in imports generated by household consumption. The study revealed that manufactured products and clothing and footwear together accounted for $21 \%$ of the carbon footprint of European households, $17 \%$ of their land footprint, $25 \%$ of material footprint and $16 \%$ of water footprint. While manufactured goods consumption was particularly relevant for the material footprint of EU households, food and clothing were the most and second most land-intensive and water-intensive consumption categories, respectively.

The environmental impact associated to the consumption of household goods depends not only on the intensity of the impacts resulting from the production and trade of goods but also on the consumption intensity defined by the lifestyle of people. Consequently, reducing the impact of household consumption should entail solutions ranging from responsible sourcing of raw materials and ecoinnovation of the production processes to changes in lifestyles and consumption habits (UN 2015).

Household income has been identified as one of the main determinants of households' carbon footprint, with carbon footprints increasing with increasing incomes, along with household size and composition, rural or urban location and type of energy supply (Druckman and Jackson 2016). The link between available income and environmental impacts of household consumption has been underlined in the literature (e.g. Ivanova et al. 2016; Kalbar et al. 2016; Tukker et al. 2010; Büchs and Schnepf 2013; Duarte et al. 2010), including potential rebound effects driven by individual behaviour (Font Vivanco et al. 2018).

By providing a more comprehensive picture on the role of household goods and their environmental impacts, the present study aims at assessing the environmental impacts 
of the consumption of household goods in Europe considering a life cycle perspective. The study builds on the Consumption Footprint indicator project conducted by the European Commission-Joint Research Centre (EC-JRC) since 2010 (EC-JRC 2012a, 2012b; Sala and Castellani, 2019). The project aims at comprehensively assessing different areas of consumption with a bottom-up LCA-based approach at the scale of the entire Europe. The rationale is to build a baseline set of indicators, i.e. Consumption Footprint, to monitor the impacts of consumption patterns over time and to run scenarios against the baseline to test the extent to which different innovations or intervention may help reducing the impacts. Five key areas of consumption have been investigated, i.e. housing (Baldassarri et al. 2017; Lavagna et al. 2018), mobility (Castellani et al. 2017a), food (Notarnicola et al. 2017; Castellani et al. 2017b), household appliances (Reale et al. 2019; Hischier et al. 2020) and household goods. The object of the present paper is the last one, i.e. household goods. For each area of consumption, a process-based life cycle inventory (LCI) model for a basket of representative products $(\mathrm{BoP})$ is built, representing the most relevant product groups in the considered area of consumption, selected by importance in mass and economic value based on statistics on consumption and stock of products. The goal of this paper is to illustrate the assessment of the environmental impacts of household goods consumption in the EU, through the implementation of the BoP household goods, which includes products that relate to the daily life of a household (e.g. detergents, personal care products, furniture, as illustrated in Table 1). For this purpose, the specific objectives of this study are twofold: (a) detailing the methodology to model and to assess the BoP household goods and the related results and (b) discussing the specific methodological challenges arising from the application of the consumption footprint framework to the household goods sector.

The paper is organized as follows: Sect. 2 illustrates the steps followed to apply the Consumption Footprint approach to the household goods sector, and Sect. 3 illustrates the results of the Consumption Footprint of household goods in Europe. Finally, Sect. 4 discusses the main hotspots and the methodological challenges identified and draws conclusions on the feasibility of assessment of Consumption Footprint of household goods and the robustness of the results obtained.

\section{Method}

The impact of household goods consumption in EU-27 is assessed following the Consumption Footprint approach, as described in Sala and Castellani (2019). The definition and characterization of the household goods sector was performed at the EU level to assess the environmental impacts of the EU-27 household goods representative basket of products (BoP household goods) for the reference year 2010. Note that previous versions of the Consumption Footprint indicator were termed as consumer footprint. In the current framework, the indicator is termed consumption footprint with the ambition to assess the environmental impacts of EU and Member States consumption at a macro-scale level and based on consumption statistics.

The selection of the product groups to be included in the basket was based mainly on the list of product groups already covered by the EU Ecolabel (EC 2010) and Green Public Procurement (GPP) criteria (EC 2004), complemented with the product groups in the household goods sector for which a Product Environmental Footprint (PEF) (EC 2013) pilot was ongoing at the time of the study (2018). The reason of this choice was twofold: on the one hand, the product groups that are covered by EU Ecolabel or GPP criteria are selected based on their market significance in terms of stock volume and sales and importance of the environmental impact generated. This is in line with the rationale for the selection of the representative products for the other BoPs (e.g. for BoP food and BoP appliances). On the other hand, one of the aim of the study on BoP household goods was to support the analysis of the environmental savings potential related to the implementation of non-energy requirements coming from the Ecodesign, EU Ecolabel and GPP policies (for more details on the scenarios analysed, see the technical report on consumption footprint of household goods, Castellani et al 2019a). Therefore, it was important that the BoP had a scope that is similar to the ones of the abovementioned policies.

Based on these criteria, eight product groups were selected, namely detergents, sanitary products (absorbent hygiene products), personal care (rinse-off cosmetics), furniture, bed mattresses, footwear, clothes and paper products. This selection led to the inclusion of 30 representative products (Table 1).: 
Table 1 Composition of the BoP household goods in terms of product groups, representative products and apparent consumption for 2010 and 2015 (referred to the reference flow, i.e. household goods consumption of an average EU citizen in the reference year) ( source: Eurostat 2019b)

\begin{tabular}{|c|c|c|c|c|c|c|c|c|}
\hline \multirow[t]{2}{*}{ Product group } & \multirow[t]{2}{*}{ Representative product } & \multirow[t]{2}{*}{ Unit $^{\mathrm{a}}$} & \multirow[t]{2}{*}{$\begin{array}{l}\text { Total apparent } \\
\text { consumption (unit/y) } \\
(2010)\end{array}$} & \multirow[t]{2}{*}{$\begin{array}{l}\text { Per-capita apparent } \\
\text { consumption (unit/ } \\
\left.\text { citizen* }{ }^{-1}\right)(2010)\end{array}$} & \multirow[t]{2}{*}{$\begin{array}{l}\text { Coverage by repre- } \\
\text { sentative products } \\
(2010)\end{array}$} & \multicolumn{2}{|c|}{$\begin{array}{l}\text { Per capita } \\
\text { upscaled appar- } \\
\text { ent consump- } \\
\text { tion }(\text { unit/ } \\
\left.\text { citizen* }{ }^{-1}\right) \\
\end{array}$} & \multirow[t]{2}{*}{$\begin{array}{l}\text { Variation } \\
2010-2015 \\
(\%)\end{array}$} \\
\hline & & & & & & 2010 & 2015 & \\
\hline \multirow[t]{5}{*}{ Detergents } & $\begin{array}{l}\text { All-purpose cleaners } \\
\text { and sanitary cleaners }\end{array}$ & $\mathrm{kg}$ & $5,020,703,455$ & 9.99 & $100 \%$ & 9.99 & 11.32 & $13 \%$ \\
\hline & $\begin{array}{l}\text { Detergents for dish- } \\
\text { washers }\end{array}$ & $\mathrm{kg}$ & $1,220,288,309$ & 2.43 & $100 \%$ & 2.43 & 2.75 & $13 \%$ \\
\hline & $\begin{array}{l}\text { Hand dishwashing } \\
\text { detergents }\end{array}$ & $\mathrm{kg}$ & $878,530,349$ & 1.75 & $100 \%$ & 1.75 & 1.98 & $13 \%$ \\
\hline & $\begin{array}{l}\text { Liquid laundry deter- } \\
\text { gents }\end{array}$ & $\mathrm{kg}$ & $5,040,246,743$ & 10.03 & $100 \%$ & 10.03 & 11.36 & $13 \%$ \\
\hline & $\begin{array}{l}\text { Powder laundry } \\
\text { detergents }\end{array}$ & $\mathrm{kg}$ & $1,558,000,147$ & 3.10 & $100 \%$ & 3.10 & 3.51 & $13 \%$ \\
\hline \multirow{4}{*}{$\begin{array}{l}\text { Sanitary products } \\
\text { (absorbent hygiene } \\
\text { products) }\end{array}$} & Baby diapers & $\mathrm{kg}$ & $786,735,433$ & 1.57 & $49 \%$ & 3.22 & 5.24 & $63 \%$ \\
\hline & Sanitary pads & $\mathrm{kg}$ & $991,362,870$ & 1.97 & $49 \%$ & 4.05 & 6.44 & $59 \%$ \\
\hline & Tampons & $\mathrm{kg}$ & $22,536,286$ & 0.04 & $49 \%$ & 0.09 & 0.14 & $54 \%$ \\
\hline & Breast pads & $\mathrm{kg}$ & $135,840,184$ & 0.27 & $49 \%$ & 0.56 & 0.91 & $63 \%$ \\
\hline \multirow{4}{*}{$\begin{array}{l}\text { Personal care (rinse-off } \\
\text { cosmetics) }\end{array}$} & Bar soap & $\mathrm{kg}$ & $718,676,400$ & 1.43 & $31 \%$ & 4.59 & 4.06 & $-12 \%$ \\
\hline & Liquid soap & $\mathrm{kg}$ & $285,135,500$ & 0.57 & $31 \%$ & 1.82 & 4.18 & $130 \%$ \\
\hline & Shampoo & $\mathrm{kg}$ & $490,190,553$ & 0.98 & $31 \%$ & 3.13 & 2.04 & $-35 \%$ \\
\hline & Hair conditioner & $\mathrm{kg}$ & $324,550,414$ & 0.65 & $31 \%$ & 2.07 & 1.26 & $-39 \%$ \\
\hline \multirow[t]{5}{*}{ Furniture } & $\begin{array}{l}\text { Bedroom wooden } \\
\text { furniture }\end{array}$ & $\mathrm{p}$ & $65,991,756$ & 0.131 & $66 \%$ & 0.20 & 0.19 & $-2 \%$ \\
\hline & Kitchen furniture & $\mathrm{p}$ & $99,635,746$ & 0.198 & $66 \%$ & 0.30 & 0.27 & $-10 \%$ \\
\hline & Upholstered seat & $\mathrm{p}$ & $62,131,672$ & 0.124 & $66 \%$ & 0.19 & 0.15 & $-19 \%$ \\
\hline & $\begin{array}{l}\text { Non-upholstered seat } \\
\text { (wooden seat) }\end{array}$ & $\mathrm{p}$ & $89,872,496$ & 0.179 & $66 \%$ & 0.27 & 0.18 & $-35 \%$ \\
\hline & $\begin{array}{l}\text { Dining room furniture } \\
\text { (wooden table) }\end{array}$ & $\mathrm{p}$ & $54,735,761$ & 0.109 & $66 \%$ & 0.17 & 0.18 & $10 \%$ \\
\hline Bed mattresses & $\begin{array}{l}\text { Mattress (Latex, PUR } \\
\text { and spring mat- } \\
\text { tresses) }\end{array}$ & $\mathrm{p}$ & $39,946,072$ & 0.079 & $89 \%$ & 0.09 & 0.10 & $10 \%$ \\
\hline \multirow[t]{4}{*}{ Footwear } & $\begin{array}{l}\text { Work and waterproof } \\
\text { (WW) }\end{array}$ & pa & $120,544,539$ & 0.24 & $50 \%$ & 0.48 & 0.45 & $-7 \%$ \\
\hline & Sport & pa & $152,705,002$ & 0.30 & $50 \%$ & 0.61 & 0.82 & $35 \%$ \\
\hline & Leisure & pa & $575,848,245$ & 1.15 & $50 \%$ & 2.29 & 2.13 & $-7 \%$ \\
\hline & Fashion & pa & $575,848,245$ & 1.15 & $50 \%$ & 2.29 & 2.13 & $-7 \%$ \\
\hline \multirow[t]{4}{*}{ Clothes $^{\mathrm{b}}$} & T-shirt & $\mathrm{p}$ & $3,533,705,142$ & 7.03 & $22 \%$ & 31.80 & 34.70 & $9 \%$ \\
\hline & Women blouse & $\mathrm{p}$ & $949,656,480$ & 1.89 & $22 \%$ & 8.55 & 9.32 & $9 \%$ \\
\hline & Men trousers & $\mathrm{p}$ & $415,925,233$ & 0.83 & $22 \%$ & 3.74 & 4.08 & $9 \%$ \\
\hline & Jeans & $\mathrm{p}$ & $532,586,108$ & 1.06 & $22 \%$ & 4.79 & 5.22 & $9 \%$ \\
\hline \multirow[t]{3}{*}{ Paper products } & Newspaper & $\mathrm{kg}$ & $13,958,343,439$ & 45.99 & $31 \%$ & 90.50 & 85.05 & $-6 \%$ \\
\hline & Book & $\mathrm{kg}$ & $2,969,875,678$ & 5.91 & $31 \%$ & 19.26 & 25.07 & $30 \%$ \\
\hline & Toilet paper & $\mathrm{kg}$ & $3,631,492,140$ & 7.23 & $31 \%$ & 23.55 & 36.39 & $55 \%$ \\
\hline
\end{tabular}

$p$ pieces, $p a$ pair

${ }^{a}$ Units as in PRODCOM database

${ }^{\mathrm{b}}$ The amount of clothes in 2015, and resulting variation from 2010, is based on the economic value increase of the whole textile sector due to a low robustness of considered data

${ }^{\mathrm{c}}$ Total apparent consumption, per capita apparent consumption and coverage by representative products for 2015 are detailed in Table S3 
Table 2 Results of characterization, normalization and weighting of the BoP household goods (2010) (EF 3.0 method)

\begin{tabular}{|c|c|c|c|c|}
\hline Impact category & Unit & Characterization & Normalization & Weighting \\
\hline Climate change & $\mathrm{kg} \mathrm{CO}_{2}$ eq & $7.48 \mathrm{E}+11$ & $1.34 \mathrm{E}-02$ & $27.3 \%$ \\
\hline Ozone depletion & kg CFC-11 eq & $5.97 \mathrm{E}+04$ & $1.61 \mathrm{E}-04$ & $0.1 \%$ \\
\hline Human toxicity, non-cancer & CTUh & $7.64 \mathrm{E}+03$ & $4.82 \mathrm{E}-03$ & $1.0 \%$ \\
\hline Human toxicity, cancer & CTUh & $4.11 \mathrm{E}+02$ & $3.53 \mathrm{E}-03$ & $0.6 \%$ \\
\hline Particulate matter & Disease incidence & $3.90 \mathrm{E}+04$ & $9.50 \mathrm{E}-03$ & $8.2 \%$ \\
\hline Ionizing radiation, human health & $\mathrm{kBq} \mathrm{U}^{235} \mathrm{eq}$ & $4.47 \mathrm{E}+10$ & $1.53 \mathrm{E}-03$ & $0.7 \%$ \\
\hline Photochemical ozone formation, human health & $\mathrm{kg}$ NMVOC eq & $2.13 \mathrm{E}+09$ & $7.59 \mathrm{E}-03$ & $3.5 \%$ \\
\hline Acidification & molc $\mathrm{H}^{+}$eq & $4.10 \mathrm{E}+09$ & $1.07 \mathrm{E}-02$ & $6.4 \%$ \\
\hline Eutrophication, terrestrial & molc $\mathrm{N}$ eq & $8.17 \mathrm{E}+09$ & $6.70 \mathrm{E}-03$ & $2.4 \%$ \\
\hline Eutrophication, freshwater & $\mathrm{kg} \mathrm{P}$ eq & $5.55 \mathrm{E}+07$ & $5.00 \mathrm{E}-03$ & $1.4 \%$ \\
\hline Eutrophication, marine & $\mathrm{kg} \mathrm{N} \mathrm{eq}$ & $1.14 \mathrm{E}+09$ & $8.47 \mathrm{E}-03$ & $2.4 \%$ \\
\hline Ecotoxicity, freshwater & CTUe & $1.92 \mathrm{E}+13$ & $2.67 \mathrm{E}-03$ & $2.0 \%$ \\
\hline Land use & $\mathrm{Pt}$ & $1.31 \mathrm{E}+13$ & $4.46 \mathrm{E}-02$ & $8.3 \%$ \\
\hline Water use & $\mathrm{m}^{3}$ water eq & $1.06 \mathrm{E}+12$ & $1.34 \mathrm{E}-02$ & $11.1 \%$ \\
\hline Resource use, fossils & MJ & $1.10 \mathrm{E}+13$ & $2.46 \mathrm{E}-02$ & $19.7 \%$ \\
\hline Resource use, minerals and metals & $\mathrm{kg} \mathrm{Sb} \mathrm{eq}$ & $2.91 \mathrm{E}+06$ & $6.63 \mathrm{E}-03$ & $4.8 \%$ \\
\hline Total & & - & $1.63 E-01$ & $100 \%$ \\
\hline
\end{tabular}

The impact of the overall consumption of household goods is accounted for as the sum of the product of consumption intensity (Sect. 2.1) (consumption intensity units depends on the product, Table 1) and the impact intensity of each representative product (i) (Sect. 2.2) (impact units depends on impact category, Table 2) as in Eq. 1. The environmental impacts are assessed using the Environmental Footprint (EF) 3.0 method (Sect. 2.3).

BoP impact $($ impact unit $)=\sum_{i=0}^{n}$ Consumption intensity ${ }_{i}($ consumption unit $) *$ Impact intensity $_{i}\left(\frac{\text { impact unit }}{\text { consumption unit }}\right)$

consumption of the associated product groups. The representativeness of the products is relatively low (in some cases, below $50 \%$ of the entire product group) (Table S1). For example, the four representative products of "sanitary products" (3.85 kg/person* year $^{-1}$ ) represent only $49 \%$ of the EU consumption per capita for the entire product group $\left(7.92 \mathrm{~kg} /\right.$ person $^{*}$ year $^{-1}$ ) (i.e. including also other types of sanitary products, not modelled in the BoP). Therefore, to where consumption intensity is defined as ProductionExports + Imports.

\subsection{Consumption intensity of representative products}

A quantitative and qualitative analysis of the structure of EU-27 household goods consumption was performed for the selected product groups, including an analysis of international trade. Data on apparent consumption (defined as Production-Exports + Imports) of the representative products were collected from the Prodcom database (Eurostat 2019b) (Table 1).

A coverage analysis was performed to assess the representativeness of the BoP-in terms of quantity (in mass, pieces or pairs) and of value $(€)$ - for identifying to which extent the apparent consumption of the representative products included in the BoP could represent the overall represent the total amount of sanitary products consumed, the quantity of these four representative products should be upscaled to $100 \%$ (i.e. $7.92 \mathrm{~kg} /$ person* $^{*}$ year $^{-1}$ ).

This upscale step is an approximation assuming that the impact of the representative products selected for the product (e.g. t-shirt, blouse, trousers, jeans) may be representative for the impact of other kind of products not included in the BoP from the respective product group (e.g. other type of clothes like skirts, suits or coats). However, it was deemed more useful to have this approximation instead of underrepresenting the actual consumption of the product groups considered. When choosing the upscale factor for each product group, priority was given to mass or quantity data, whereas value was used only when data about quantity and mass were considered not suitable for upscaling due to big data gaps (e.g. the Prodcom records did not include import and export data for some product groups). Specific comments for each product group are reported in Table S1. 
Finally, note that the product groups included in the BoP do not represent all the types of household goods consumed by EU citizens. Some product groups (e.g. pharmaceuticals, toys, crockery and cutlery or single use plastic items) have not been considered in this study and are generally missing in this kind of studies, even if they might generate significant environmental impacts not only in the production stage but also during use. Moreover, only physical products are included, thereby excluding the environmental impacts associated to matterless consumption, i.e. services. The relevance of services could be assessed by means of an environmentally extended input-output analysis (EEIO) approach (Beylot et al. 2020).

\subsubsection{Quantities of representative products for a different reference year}

The baseline scenario of the BoP refers to the baseline year 2010, and, consequently, to EU-27. This year was chosen because it was the closest year for which a more complete set of data on apparent consumption was available in 2014, when the modelling of BoPs started. However, in the meantime from 2010 to today (2021), there has been a variation of the number of Member States of the European Union (from 27 to 28, with the inclusion of Croatia, and back to 27 with the withdrawal of United Kingdom) leading to variations in EU population. Moreover, not only EU population but also consumption patterns may change from year to year, influencing the results of the BoP's assessment. An updated baseline scenario was therefore also modelled, as a sensitivity analysis, aimed at understanding how much the choice of the reference year may influence the results. The analysis was conducted taking 2015 as reference year and enlarging the geography from EU-27 to EU-28. Consequently, the reference population was updated (from 502 million citizens in 2010 in EU-27 to 508 million citizens in 2015 in EU-28). On the contrary, potential technological changes between the two reference years were considered to have only limited effect on the inventory of products, due to the limited time span considered. Therefore, no changes at the inventory level were implemented. Note that although the composition of the EU has currently changed to 27 Member States, this study assesses the composition of the EU during the time period evaluated (2010 and 2015) thereby still including the UK.

The analysis of a different reference year implied the calculation of updated consumption intensity (Table 1) and upscale factors (Table S2) based on consumption statistics. When choosing between the upscale factor derived from the representativeness in mass or value, priority was given to the type of upscale factor already used for the analysis on the reference year 2010. However, this was deemed not suitable for paper products, because quantity data for newspapers and other printed products included in the basket were not available in Prodcom records. Therefore, data on coverage by value were considered for the study (differently from what was done for 2010).

The choice of the reference year has a large influence on the consumption intensity of representative products based on apparent consumption leading to both significant increases, some goods (e.g. liquid soap) showing an increase higher than $100 \%$, and decreases, some products (e.g. hair conditioner) showing a reduction close to $40 \%$ (Table 1 ). This variation results from the combined fluctuation of two variables: the apparent consumption of representative products and the upscale factor resulting from their representativeness of the whole product group. Therefore, it should be interpreted with caution, because of the limited number of representative products included in the basket and the uncertainty in the upscale of quantities.

\subsection{Life cycle inventory of the BoP}

The reference system is the EU-27 per capita consumption in 2010 for the BoP products (Table 1). The reference flow is defined as the consumption of household goods by an average EU citizen in 1 year (reference year 2010). A cradleto-grave approach is applied to define the system boundaries, thereby considering all the stages of the life cycle of representative products (Fig. 1). The geographical reference of the functional unit corresponds to the EU composition at the time of the assessment: in 2010 the EU was composed of 27 Member States including the UK and still not considering Croatia, while in 2015, the EU included already Croatia totalling in 28 Member States.

For each representative product, a LCI has been compiled with data prioritizing the collection from background reports compiled for the definition of Ecolabel criteria (see the supplementary materials for the detailed references) (ECJRC, 2017) and from the screening reports of the PEF pilots (EC 2018), since they are based on a market analysis and on stakeholders' feedback. When a complete LCI was not available in these sources, data were collected from scientific literature, technical reports or Environmental Product Declarations (EPDs). The ecoinvent database v3.2 was used for background LCI data (e.g. electricity production, transport) (Wernet et al. 2016). The database version was chosen as the most updated one at the beginning of the exercise and with temporal representativeness (1992-2010) covering the baseline year (2010). Updates of the indicator and underpinning data may take place along time and can be consulted in the European Platform on Life Cycle Assessment (ECJRC 2021). The following sub-sections detail the assumptions and the data sources by life cycle stage. 


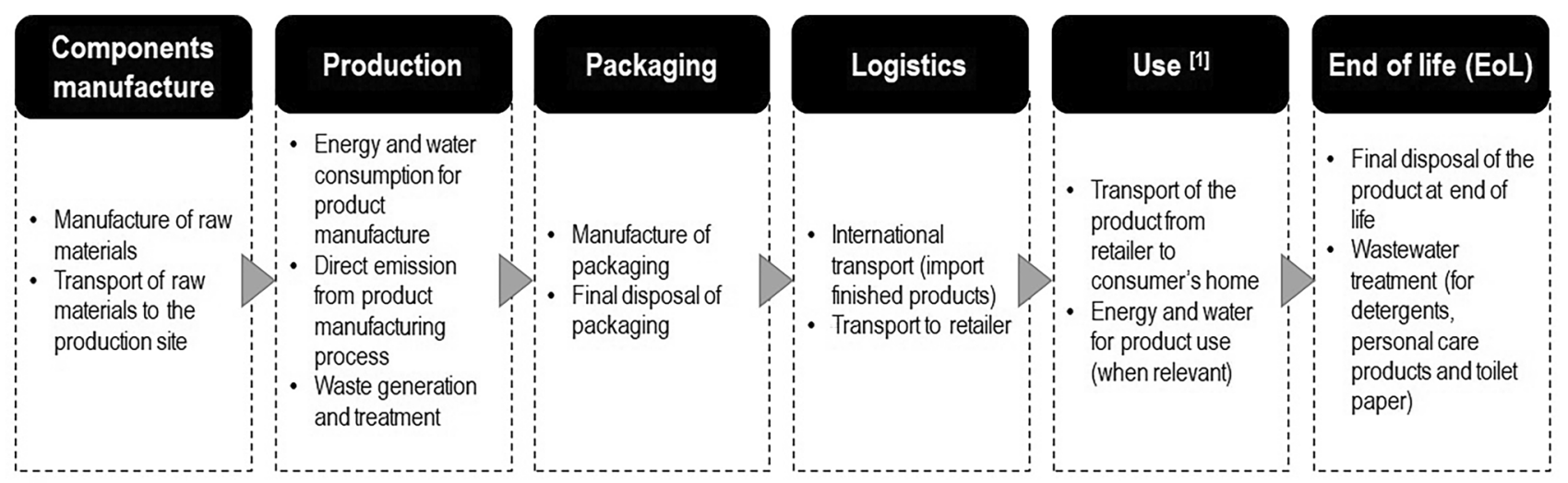

[1] Use phase of clothes (i.e. washing clothes) is not included in the model to avoid double counting with the use phase of detergents

Fig. 1 Summary of life cycle stages and related activities included in the BoP household goods

To ensure consistency in the development of LCIs of representative products, data retrieved from original sources (e.g. Ecolabel background reports and PEF pilot studies) were aligned, as much as possible, in terms of system boundaries and general assumptions. The main cross-cutting assumptions regard transport activities (e.g. modelling of logistics and calculation of import shares and distances), electricity use (either in the use phase, i.e. using the same dataset to model EU electricity mix, and in the way in which the electricity mix of the production phase happening in trading countries has been modelled, as described in Sect. 2.2.2 and in Tables S4 and S5) and modelling of end of life scenarios (as described in Sect. 2.2.6.).

The functional unit of the individual representative products considered one unit of a product for an expected lifespan, in line with the considered data sources and approaches employed in the literature for consumer goods such as furniture (Cordella and Hidalgo 2016). The products included in the BoP household goods are mainly considered to be consumed within the 1 year timeframe of the Consumption Footprint, apart from bed mattresses (10 years), furniture (15 years) and books (10 years) with a longer lifespan.

\subsubsection{Components' manufacture}

The bill of materials (BoM) for each of the representative products was taken from the reference sources reported in Table S4 (detailed BoMs available in Castellani et al. (2019a)). This stage includes also the transport of raw materials to the production site. When specific data about transport distances and modes were not available in the sources used to model the representative products, transport was modelled according to PEF Category Rules (PEFCRs) (EC 2017).

\subsubsection{Production}

The inventory was built for each activity included in the production phase of each product from data sources (Table S4). Regarding electricity consumption in the production phase, the model takes into account that a share of products consumed in Europe is produced in foreign countries. Therefore, the European electricity mix ("Electricity, low voltage \{Europe without Switzerland\}। market group" from ecoinvent 3.2 library) was used for the share of production that is known to take place in Europe. In addition, for the share of production known to occur outside Europe, a specific electricity mix was created to represent the real conditions of the production sites. The electricity mix for imported goods is built considering the share of each product group that is imported from each extra-EU country where production occurs, based on trade statistics (Eurostat 2019a), in order to cover at least $90 \%$ of the imported quantity for each representative product. For footwear and clothes, specific electricity mix data based on the most relevant production sites for those products was gathered from PEF screening reports. The list of extra-EU trade countries with related contribution to the extra-EU production electricity mix used for each of the product groups is detailed in Table S5.

\subsubsection{Packaging}

Packaging (Table S6) includes both primary and secondary packaging, being modelled consistently to data sources (Table S4). It is assumed that newspapers and books are sold without packaging. 


\subsubsection{Logistics}

Logistics consists of international transportation from outside the EU, transport of processed goods from industry to retailing and the retailing stage itself. Transport from the manufacturing site to retailing was modelled considering data provided by each data sources listed in Table S4. In addition, international transport of imported finished products was added for the share of goods in each product group that is imported from extra-EU countries. The share of imported goods (production minus export plus import) was calculated based on trade statistics (Eurostat 2019a), and it is reported in Table S7. International transport was modelled considering transport distance and mode of transport (e.g. only by road, or road and sea, depending on the country). The transport distance was assumed to occur from the capital of the exporting country to the city of Frankfurt, which was considered a central destination for the arrival of imports in Europe, considering both sea (transoceanic cargo) and road transport (lorry). For those exporting countries overseas, the transport was composed by a transport by lorry between the capital of the exporting country and the country's main port; a transport by ship from the port of the exporting country to the main European ports (Rotterdam and Marseille); and, finally, a transport by lorry between the port of destination and the city of Frankfurt. Sea and road transport distances for each exporting country were calculated by using www.sea-distances.org and Google maps, respectively. Then, a weighted transport distance based on exporting countries identified for each product group and respective share of imported goods was calculated for each of the product groups considered in the BoP model. The resulting transport distances are reported in Table S7.

\subsubsection{Use phase}

The use phase comprises the transport to the consumers' home and the use of the product at home. While for big products (furniture and bed mattresses) the transport from retail was considered to be done by lorry (i.e. it was modelled considering the weight of the product multiplied by the distance), the transport of small products was assumed to be done by the final consumer by car. A transport distance of $4 \mathrm{~km}$ was considered for this transport; it is also assumed that an average shopping by final consumer at the supermarket includes 30 products, so only one thirtieth of the transport is allocated to each unit of small products (Vanderheyden and Aerts 2014).

Regarding the use of the product, this was considered null or negligible for some of products (i.e. sanitary products, furniture, bed mattresses and paper products). However, use is a relevant stage in the whole life cycle for some other type of products and was modelled in detail (Table S8). The modelling of this stage considered also the prevention of double counting of impacts. For instance, the use phase of clothes involves the consumption of detergents and implies the use of water and electricity. To prevent double counting, electricity and water use were fully allocated to the detergents' life cycle (as in the original source, i.e. Ecolabel background report). This assumption leads, however, to a lower impact of clothes as a product group compared to studies where the life cycle of clothes has been assessed individually and should be considered when analysing results at the product category level. Moreover, a possible double counting may occur in the use of shampoo and hair conditioner (both used in the washing of the hair) in the case of personal care products. A 50\%-50\% allocation criterion of the water used was implemented, i.e. $50 \%$ to the shampoo and $50 \%$ to the hair conditioner. Coherently with the assumptions made in the original source (Ecolabel background report), energy requirements for water heating or hair drying were excluded from the system boundaries, as they are optional and not directly related to the products. Notwithstanding that the use phase can be affected by specific characteristics of the products and the behaviour of the user (e.g. energy efficiency, resource efficiency, lifespan and reparability), this study has followed the assumptions of the original sources. However, the granularity of the BoP model allow assessing specific scenarios addressing consumers' behaviours, e.g. reusing products like clothing or furniture (Castellani et al. 2019a).

\subsubsection{End of life (EoL)}

The end of life (EoL) stage in the BoP was modelled considering the burdens and benefits of recycling and the burdens of waste treatment of non-recycled waste. Recycling rates were taken from data sources (Table S4). For products with lack of data or negligible recycling considered, an unsorted municipal waste stream was assumed (55\% landfill and $45 \%$ incineration) (Table S8). The EoL of packaging was included in the packaging stage.

\subsection{Life cycle impact assessment}

The upscaled inventory of the BoP household goods was characterized, normalized and weighted using the EF 3.0 method (EC-JRC 2018; Fazio et al. 2018; Zampori and Pant 2019). Global normalization factors have been adapted from Crenna et al. (2019) — with corrections in specific elementary flows - and the weighting of the EF method has been employed (Sala et al. 2018). The 16 impact categories of the EF 3.0 method include climate change (CC); ozone depletion (ODP); human toxicity, non-cancer (HTOX_nc); human toxicity, cancer (HTOX_c); particulate matter (PM); ionizing radiation (IR); photochemical ozone formation 


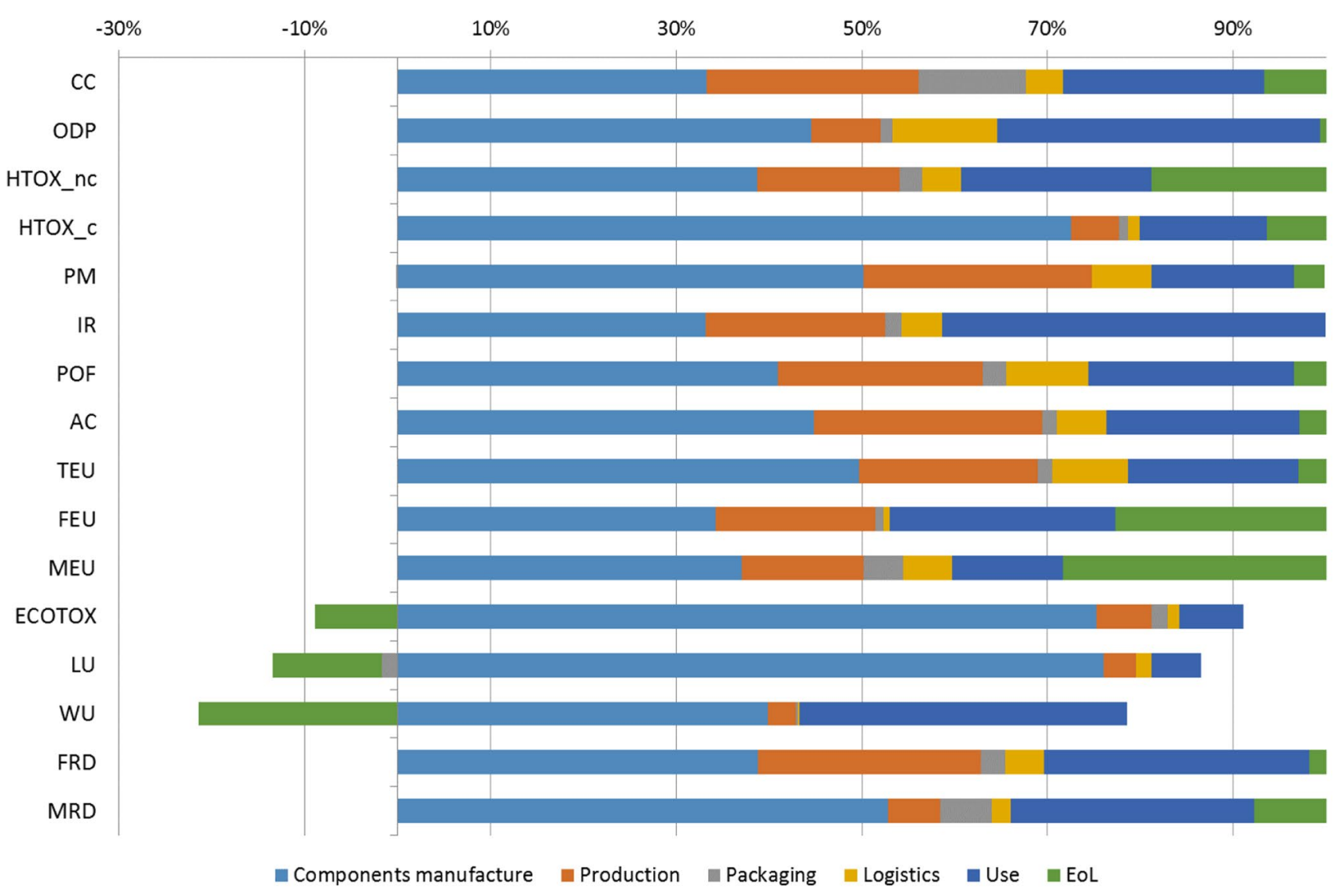

Fig. 2 Contribution of different life cycle stages to characterized results of the BoP household goods. Note: Negative impacts result from the environmental benefits associated to the recycling of products (EoL) and of packaging (packaging)

(POF); acidification (AC); eutrophication, terrestrial (TEU); eutrophication, freshwater (FEU); eutrophication, marine (MEU); land use (LU); ecotoxicity freshwater (ECOTOX); water use (WU); resource use, fossils (FRD); and resource use, minerals and metals (MRD).

\section{Results}

Characterized, normalized and weighted results referred to the impacts generated in the reference year 2010 (baseline scenario for the BoP Household goods) are presented in Table 2. Among the 16 assessed impact categories, main impacts generated by household goods' consumption in EU-27 (calculated applying normalization and weighting to characterized results) are the impacts on climate change (27.3\%), fossil resource use $(19.7 \%)$ and water use $(11.1 \%)$. To a lesser extent, the impacts on land use (8.3\%), particulate matter $(8.2 \%)$ and acidification $(6.4 \%)$ are also relevant contributing to around one-fifth of the impacts.

Components' manufacture is the most impacting stage for several impact categories (Fig. 2), mainly associated to large impacts in raw materials production or their processing. The agricultural phase of natural-based raw materials (e.g. cotton, rape oil and wood used, respectively, for clothes, soaps and furniture and paper products) contributes to the impact on land use, ecotoxicity, water use, etc. Additional impact comes from the processes needed to transform raw materials into ingredients or intermediates of the final products. For instance, the production of pulp (used in sanitary products and paper products) generates emissions to water and air that may have a significant contribution to the environmental profile of the final products. Similarly, the use of chromium in tanning processes needed to transform skins and hides into leather (to be used, e.g. in footwear) generates impacts on human toxicity.

The impact of the production stage is generally due to the use of electricity and to the emissions to water and air during the manufacturing processes. Clothes production is the most relevant one, due to the large amount of electricity needed to transform the fibres into yarn, then into textile and finally into clothes. The largest share of the production of clothes, happening outside Europe, in countries with a more impacting electricity mix (e.g. China or India, where coal is a relevant source of electricity production), is a more relevant driver of impacts than the transport of goods to Europe from overseas. 


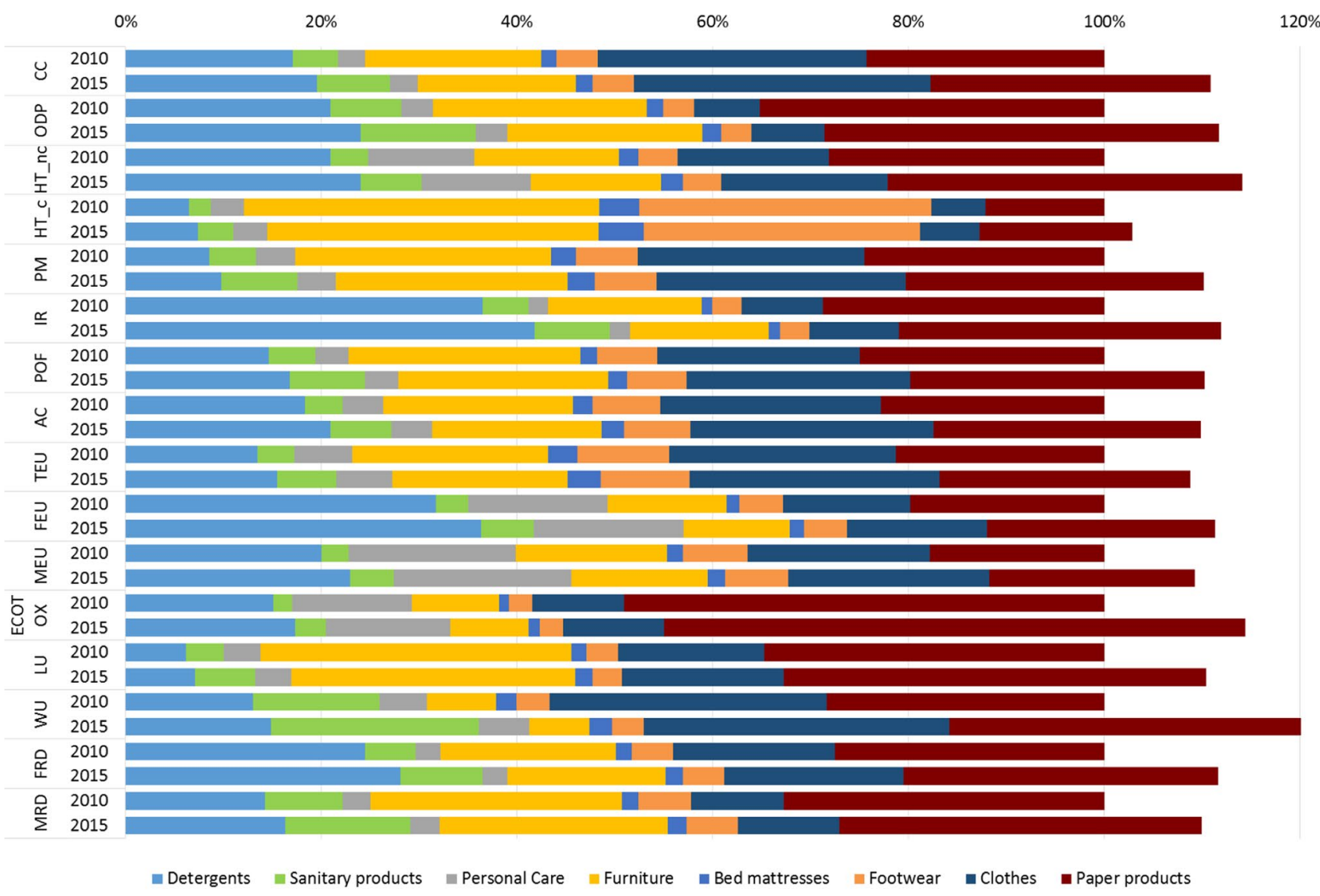

Fig. 3 Contribution by product groups at the characterization stage, years 2010 and 2015 (impact in year 2010 is taken as $100 \%$ )

Regarding the use stage, the most contributing activity is the heating of the water needed for cleaning in the use stage of detergents. For other products, the use stage does not imply any impact, except for the transport from the site of purchase to the home of the client (e.g. furniture).

Logistics has a lower contribution compared to the first stages of the life cycle of household goods. The same is for packaging ( $<10 \%$ contribution to all the impact categories), also due to the recycling of packaging at the EoL.

Finally, the EoL of some product groups helps mitigating the impacts coming from the rest of the life cycle, thanks to the credits from recycling. Within the baseline scenario of the BoP household goods, recycling is assumed to be in place only for some of the product groups (clothes and paper products), to reflect the actual situation in which recycling is mainly applied to packaging materials.

\subsection{Environmental impact intensity and consumption intensity}

Each product group in the BoP household goods has different hotspots in terms of the type of impact and the life cycle stage which is generated, being paper products, detergents, furniture and clothes the most contributing product groups (Fig. 3). This contribution is partly due to the impact intensity of the product considered (i.e. the impact generated by one unit of each representative product, illustrated in detail in Table S9) and partly to consumption intensity of each product (Table 1). When comparing these two factors (Fig. 4), three different groups can be distinguished.

Firstly, a major group including detergents, sanitary products, footwear, personal care, and most of clothes shows low impact intensity per unit and low consumption intensity, when compared to the other representative products. Note that this group is the most homogeneous, including some products with a larger environmental impact or consumption intensity, being this the particular case of some detergents resulting in a key contribution as a product group (i.e. particularly to some impact categories).

Secondly, paper products and clothes have a low impact intensity but high consumption intensity, being newspapers and t-shirt the two most consumed representative product per capita per year. These two products lead the overall contribution of their respective product groups to the overall $\mathrm{BoP}$ household goods. 
Fig. 4 Environmental footprint per unit of product (single weighted score) and consumption intensity (logarithmic scale) of the representative products for 2010 , by product group. Note: Consumption unit depends on representative product, as detailed in Table 1. Thresholds to define the different groups were based on the distribution of the results: 0.18 (environmental footprint - weighted) and 10 units/year (consumption intensity)
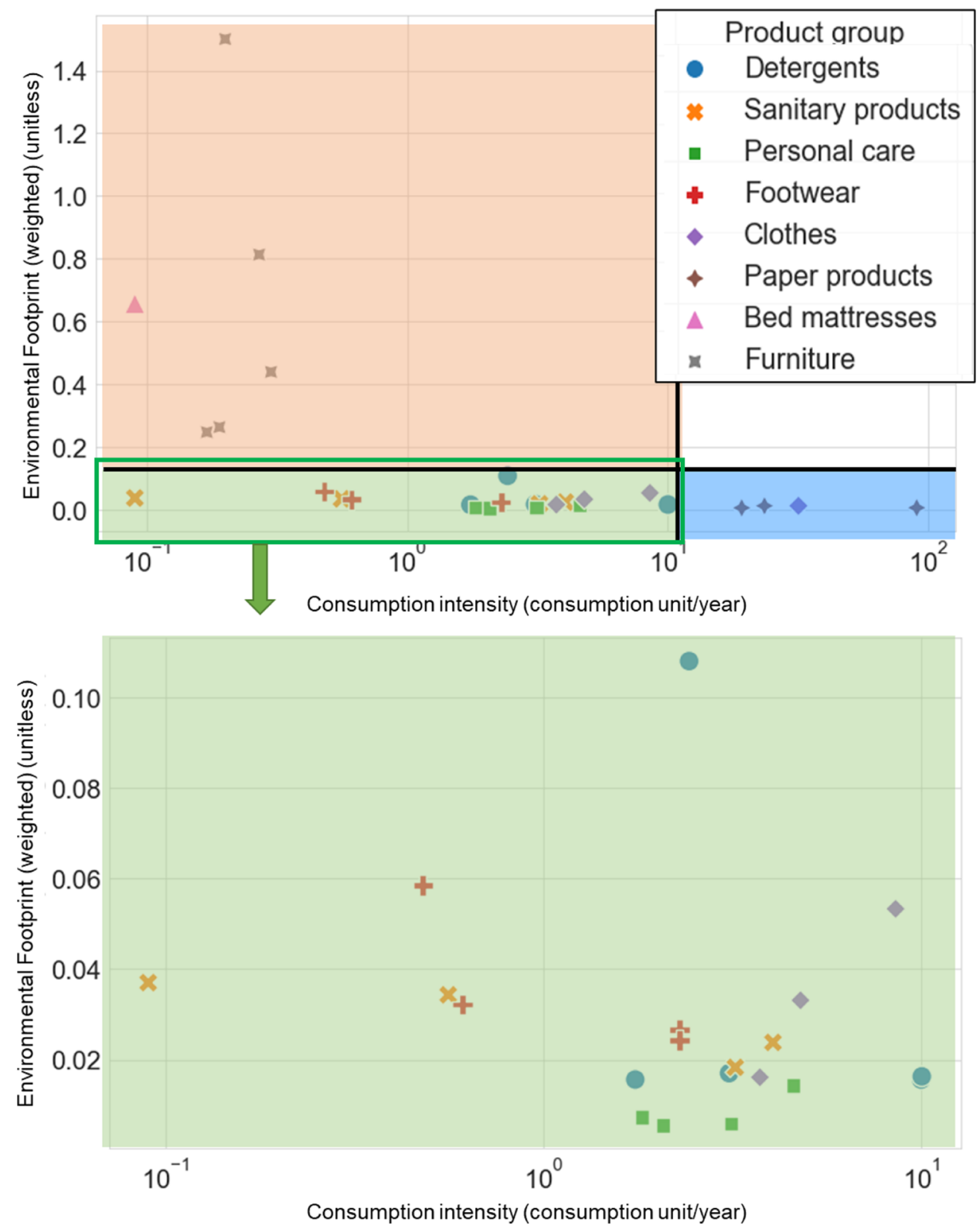

Thirdly, furniture and bed mattresses had the highest impact per unit in the different impact categories but also showed the lowest consumption intensity $(<0.3$ pieces/year per capita) together with tampons $(0.09 \mathrm{~kg} /$ year per capita).

The distribution of the different product groups regarding the environmental profile and the consumption intensity is relevant to better understand their role at the EU level. For instance, although furniture products have a large impact compared to other household goods, they contribute to the overall impact of the BoP in a similar extent than paper products and detergents due to the low consumption intensity. The different impact intensity of household goods might be related to different aspects, such as the absolute amount of resources required for a single product (e.g. furniture) or the contribution of products to specific impact categories (e.g. detergents may have ingredients that can cause relevant impact on specific impact categories, e.g. water eutrophication). However, the lifespan of furniture is longer than most of household goods which shows a relatively low consumption intensities per capita. Furthermore, this analysis has been limited to the weighted single score, thereby highlighting the role of products on the different impact categories while disguising the role of certain product groups in specific impact categories (e.g. detergents in ionizing radiation or eutrophication) (Fig. 3). 
Fig. 5 Single weighted score for 2010 and 2015, with three upscale options: baseline, upscale by quantity and upscale by value

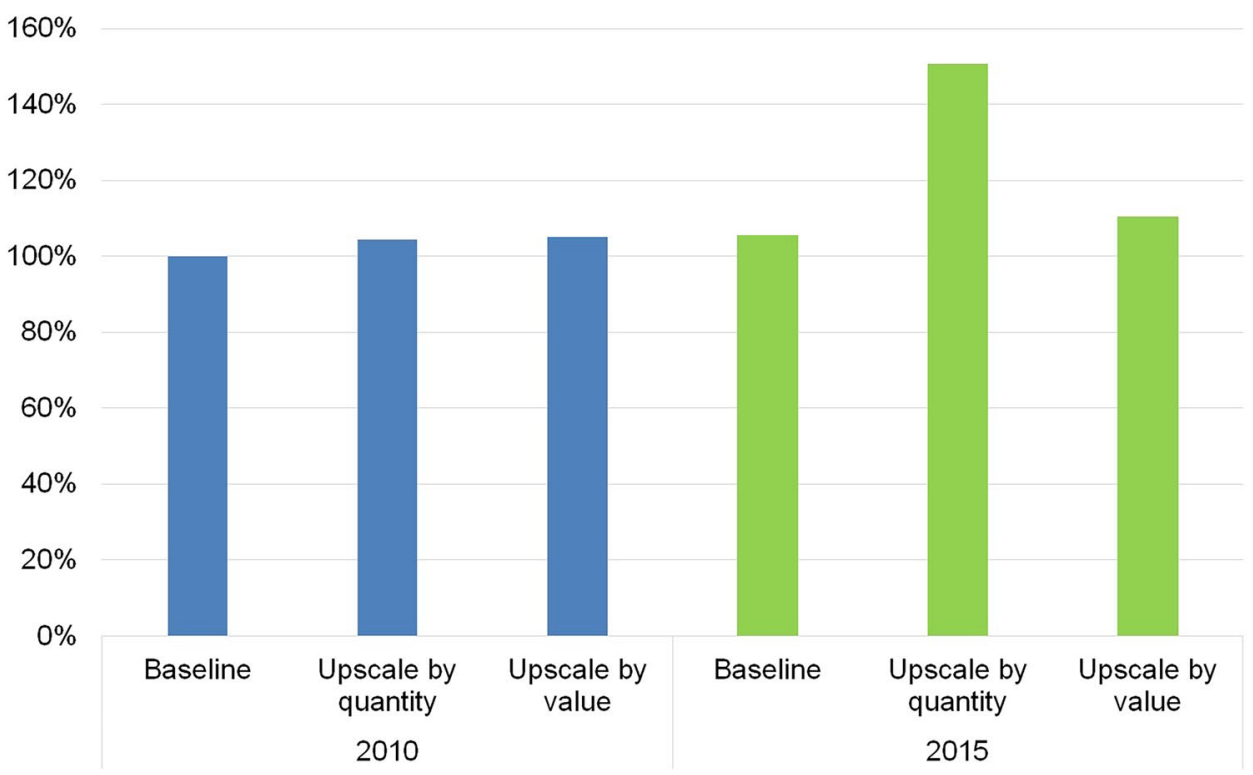

Finally, it is worthy to remark that impact intensity of products that are mainly manufactured outside Europe, such as clothes, is largely influenced by the electricity mixes of manufacturing countries, which are generally more impacting than the European one.

\subsection{Changes along time}

In general, the impact of household goods purchased and used in 2015 was higher than the one in 2010 (Fig. 3), ranging between 3\% (human toxicity, cancer effects) and 22\% (water use). Because the impact per unit is kept constant (i.e. it is assumed that the inventory of the representative products does not change between 2010 and 2015), the difference of impacts between the reference year 2010 and the year 2015 reflects only the variation of apparent consumption of each representative product. The general increase of impacts from 2010 to 2015 resulted from the combined effect of reduced apparent consumption of some products and increased apparent consumption of other products (Table 1). Thus, it is difficult to determine whether the increase of impacts from 2010 to 2015 is an effect of an increased household goods' consumption by European citizens or only an effect of fluctuations of apparent consumption due to uncertainties of statistical data (e.g. due to incomplete records) and to the assumptions made.

Consumption intensity variations may be magnified by the upscaling process of apparent consumption per representative product, especially for those groups with low coverage (e.g. paper products). A sensitivity on upscale factors defined by quantity and by value was performed unveiling a limited effect on the results for 2010 but larger variation was observed for 2015 (Fig. 5). Only upscale by quantity showed a $40 \%$ larger impact than the baseline, while other assessed options obtained similar results. Generally, the impact generated by apparent consumption of household goods in 2015 is generally higher than the one generated by apparent consumption in 2010. However, results should be interpreted with caution considering the uncertainties of data sources and the limitation of the analysis to 2 years rather than a time series.

\section{Discussion and conclusions}

The hotspot analysis conducted on the consumption footprint of EU household goods consumption highlighted three main issues. Firstly, the life cycle stage that contributes the most to the overall impact for almost all the product groups is the production of components (raw materials, ingredients or intermediate products) employed to manufacture the final product. Hence, sustainable design of household goods should focus mainly on the selection of components with lower environmental impact intensity. Secondly, the global dimension of current supply chains for household goods, and especially for some types (e.g. clothes), has an effect on the consumption footprint of the sector. The main issue is the embedded impact in imported goods associated to the electricity mix in origin countries, with higher impacts than the European mix, rather than the international transport of finished or semi-finished products (which is aligned with findings in the literature) (Sandin et al. 2019). Thirdly, the most contributing product groups are detergents, furniture, paper products and clothes. This contribution results from two combined factors: the environmental profiles (i.e. impact intensity) of the analysed representative products and their consumption intensity. Hence, actions for reducing the environmental impact of household goods sector should focus 
not only on the manufacturing processes, but also on citizens' lifestyle and purchase habits.

The most contributing life cycle stages to the consumption footprint of household goods are generally aligned with the hotspot addressed by the Ecolabel and GPP criteria for the included product groups, i.e. the choice of components/ ingredients, energy use and emissions from manufacture activities. Note that the BoP does not cover all the product groups that are part of the consumption of household goods, such as pharmaceuticals which are known drivers of some environmental impacts (e.g. due to emissions to water after use). This aspect is an inherent limitation of the bottom-up approach in comparison with top-down studies, which are able to cover the whole economy. Therefore, when interpreting the results of the BoP household goods, the potential additional impact coming from these product groups should be considered. The impact generated by some of the product groups not covered here could be considered by complementing the bottom-up approach followed for the BoP with information coming from top-down analysis (such as input-output assessment of household consumption, as discussed in Castellani et al. 2019b).

In general, the selection of representative product groups and individual products may reduce the capacity of the model to cover entirely the consumption of household goods. The selection implies the exclusion of product groups and products with a lower consumption intensity which may significantly differ in product characteristics and related impacts when compared to those selected. This is particularly relevant for areas of consumption that include a wide range of different products, as it is for household goods, which also have high variability among the same product group (e.g. the product group "personal care" includes a very wide array of products, ranging from soaps and shampoos to lipsticks, creams, etc.). In this case, the selection of a reasonable number of representative products (in terms of feasibility of data collection and of modelling) may imply (a) the exclusion of some product groups (e.g. toys, sport and recreation, pharmaceuticals), which limits the coverage of the market sector considered (household goods), and (b) a more limited representativeness of the variability within the product groups included, which may include a wider variety of product types compared to what can be done in other sectors (for instance, the choice of chairs and table as representative products for the product group "furniture" can be less representative of the whole category compared to a representative product for the product group "refrigerators" in household appliances sector). The household goods represent $13 \%$ of the total COICOP expenditure. The four COICOP categories covered by the BoP (i.e. clothing and footwear, furniture, paper products, personal care products) represent $79 \%$ of the overall household goods expenditure (i.e. $10 \%$ of all COICOP expenditure).
In the present study, the need to extend the market coverage of the model analysed has been fulfilled by upscaling the apparent consumption of the representative products chosen, in order to cover the apparent consumption of the whole product group considered. As discussed before, this action implies the choice of an upscale method, which could be based on the representativeness by quantities (mass or pieces), by the economic value or by a mix of the two (as applied in the baseline scenario presented). All these options are a source of additional uncertainty, also because the statistical records upon which the upscale is based (i.e. quantities and values for each product type in the product group) are often incomplete (see comments in Table S1). In fact, different levels of uncertainty were identified during the exercise, corresponding to (a) data gaps and outliers in consumption intensity data, (b) upscale procedure to increase the market coverage, (c) market coverage of life cycle inventory data and (d) impact assessment models. The overall uncertainty of the consumption footprint is acknowledged, and for this reason, the indicator is aimed to be used in exercises with a relative lens, namely for hotspot identification or as a baseline for monitoring or scenario modelling.

Furthermore, the choice between a bottom-up and a topdown approach should consider advantages and disadvantages of both methods. As discussed in Castellani et al (2019b), top-down studies allow assessing environmental impacts associated to the full economy and are able to provide a consistent framework for the allocation of environmental burdens generated by economic systems at macro scale to a wider range of the product categories purchased by the final consumers. However, this approach entails a lack of detail at the product level and lower possibility to analyse the impacts generated by different life cycle stages. On the contrary, as highlighted before, bottomup studies allow for a better detail of analysis at product level, but generally they lack to ensure a full coverage of the whole economy. When comparing top-down and bottom-up approaches (Castellani et al. 2019b), results cannot be directly compared due to the different granularity of economic sectors and the Consumption Footprint. However, a rough comparison can indicate similar results when comparing the contribution of household goods to the overall Consumption Footprint.

Notwithstanding these methodological limits, the present study is the first attempt to assess the entire household goods sector with a process-based LCA approach. The use of representative products and apparent consumption data may allow for periodical updates of the BoP: the amount and structure of consumption could be updated to more recent reference years using data on apparent consumption (i.e. BoP composition and relative relevance of representative products) taken from Eurostat, even with the uncertainty highlighted in Sect. 3.2. Moreover, the use of a bottom-up approach, 
with process-based inventories of representative products, allows for having more detailed life cycle inventories than in top-down approaches (such as for environmentally extended input-output tables) (Beylot et al. 2020; Castellani et al. 2019b). The availability of detailed inventories for all the life cycle phase allows for modelling scenarios to assess the potential effect of innovations in the production phase and of the choice of alternative raw materials and ingredients. Finally, this BoP model can be a good tool to analyse the effect of consumer choices, by creating and comparing consumers' profiles that differ in the composition of the BoP (e.g. a single woman or man would not need baby diapers) and in the apparent consumption (e.g. a consumer that buys three pairs of shoes each year or a consumer that buys only one pair per year).

Assessing the environmental footprint of household goods through the Consumption Footprint indicator has a specific added value for policy-making. Recent developments in EU policies under the European Green Deal (EC 2019) have highlighted the need to evaluate environmental impacts from a supply chain and consumption-based approach. Key value chains of the new Circular Economy Action Plan (EC 2020c) are associated to household goods, particularly textiles and plastics. The Zero Pollution Action Plan (EC 2021) outlined the need to increase the awareness of citizens regarding their own consumption footprints. The Consumption Footprint of household goods can be employed in the policy cycle to, for example, (a) monitor evolution of EU Consumption Footprint and the effect of policy measures, (b) have a baseline against which model policy scenarios or (c) identify hotspots at the product level contributing to specific environmental aspects.

Supplementary information The online version contains supplementary material available at https://doi.org/10.1007/s11367-021-01987-x.

Acknowledgements The present work is based on the research conducted by the Joint research Centre of the European Commission in the context of two Administrative Arrangements with the Directorate General for the Environment (DG ENV) of the European Commission, namely "Indicators and assessment of the Environmental impact of EU consumption" (N_070201/2015/SI2.705230/SER/ENV.A1) and "Application of the consumption footprint indicators in policy analysis" (No 070201/2018/790087/AA/ENV.B.1). The authors acknowledge the contribution of Jiannis Kougoulis for consumption footprint conceptualization and Carmen Hidalgo, Laura Gelabert, Maria Rosa Riera and Marta Escamilla for their technical support to the product modelling.

Data availability The data underpinning this study are available at https://eplca.jrc.ec.europa.eu/sustainableConsumption.html.

Open Access This article is licensed under a Creative Commons Attribution 4.0 International License, which permits use, sharing, adaptation, distribution and reproduction in any medium or format, as long as you give appropriate credit to the original author(s) and the source, provide a link to the Creative Commons licence, and indicate if changes were made. The images or other third party material in this article are included in the article's Creative Commons licence, unless indicated otherwise in a credit line to the material. If material is not included in the article's Creative Commons licence and your intended use is not permitted by statutory regulation or exceeds the permitted use, you will need to obtain permission directly from the copyright holder. To view a copy of this licence, visit http://creativecommons.org/licenses/by/4.0/.

\section{References}

Arena U, Ardolino F, Di Gregorio F (2016) Technological, environmental and social aspects of a recycling process of post-consumer absorbent hygiene products. J Clean Prod 127:289-301

Baldassarri C, Allacker K, Reale F, Castellani V, Sala S (2017) Consumer footprint. Basket of products indicator on housing. European Commission, Joint Research Centre, Publication Office of the European Union, Luxembourg. ISBN 978-92-79-73195-2

Beylot A, Corrado S, Sala S (2020) Environmental impacts of European trade: interpreting results of process-based LCA and environmentally extended input-output analysis towards hotspot identification. The Int J Life Cycle Assess 25(12):2432-2450. https:// doi.org/10.1007/s11367-019-01649-Z

Büchs M, Schnepf SV (2013) Who emits most? Associations between socio-economic factors and UK households' home energy, transport, indirect and total $\mathrm{CO}_{2}$ emissions. Ecol Econ 90:114-123

Castellani V, Fantoni M, Cristobal J, Zampori L, Sala S (2017a) Consumer footprint - basket of products indicator on mobility, EUR 28763 EN. Publications Office of the European Union, Luxembourg

Castellani V, Fusi A, Sala S (2017b) Consumer footprint. Basket of products indicator on food, EUR 28764 EN, Publications Office of the European Union, Luxembourg

Castellani V, Hidalgo C, Gelabert L, Riera MR, Escamilla M, Sanyé Mengual E, Sala S (2019a) Consumer footprint. Basket of products indicator on household goods, EUR 29710 EN, Publications Office of the European Union, Luxembourg, 2019, ISBN 978-9276-01613-7. https://doi.org/10.2760/908332, JRC116120

Castellani V, Beylot A, Sala S (2019b) Environmental impacts of household consumption in Europe: comparing process-based LCA and environmentally extended input-output analysis. J Clean Prod, 240, 117966

Cordella M, Bauer I, Lehmann A, Schulz M, Wolf O (2015) Evolution of disposable baby diapers in Europe: life cycle assessment of environmental impacts and identification of key areas of improvement. J Clean Prod 95:322-331

Cordella M, Hidalgo C (2016) Analysis of key environmental areas in the design and labelling of furniture products: application of a screening approach based on a literature review of LCA studies. Sustain Prod and Consump 8:64-77

Corrado S, Rydberg T, Oliveira F, Cerutti A, Sala S (2019) Out of sight out of mind? A life cycle-based environmental assessment of goods traded by the European Union. J Clean Prod, 118954.

Crenna E, Secchi M, Benini L, Sala S (2019) Global environmental impacts: data sources and methodological choices for calculating normalisation factors for LCA. The Int J Life Cycle Assess 24(10):1851-1877

Druckman A, Jackson T (2016) Understanding households as drivers of carbon emissions. In Taking Stock of Ind Ecol (pp. 181-203). Springer Int Pub

Dodson RE, Nishioka M, Standley LJ, Perovich LJ, Brody JG, Rudel RA (2012) Endocrine disruptors and asthma-associated chemicals in consumer products. Environ Health Perspect 120(7):935

Duarte R, Mainar A, Sánchez-Chóliz J (2010) The impact of household consumption patterns on emissions in Spain. Energy Econ 32(1):176-185 
EC (2004) Directive 2004/18/EC of the European Parliament and of the Council of 31 March 2004 on the coordination of procedures for the award of public works contracts, public supply contracts and public service contracts

EC (2010) Regulation (EC) No 66/2010 of the European Parliament and of the Council of 25 November 2009 on the EU Ecolabel. OJ L 27, 30.1.2010, p. 1-19

EC (2013) Building the single market for green products, $\operatorname{COM}(2013) 196$

EC (2017) PEFCR guidance document - guidance for the development of Product Environmental Footprint Category Rules (PEFCRs), version 6.3, December 2017. Available at http://ec.europa. eu/environment/eussd/smgp/pdf/PEFCR_guidance_v6.3.pdf (Accessed July 2018)

EC (2018) PEF screening reports. Available at: https://ec.europa.eu/envir onment/eussd/smgp/ef_pilots.htm\#reports (Accessed July 2019)

EC (2019) The European Green Deal. COM/2019/640 final

EC (2020a) A Farm to Fork Strategy for a fair, healthy and environmentally-friendly food system. COM/2020/381 final

EC (2020b) Biodiversity Strategy for 2030 bringing nature back into our lives. COM/2020/380 final

EC (2020c) A new Circular Economy Action Plan for a cleaner and more competitive Europe. COM/2020/98 final

EC (2021). Pathway to a healthy planet for all EU action plan: 'towards zero pollution for air, water and soil'. $\operatorname{COM}(2021) 400$ final

EC-JRC (2012a) Life cycle indicators framework: development of life cycle based macro-level monitoring indicators for resources, products and waste for the EU-27, JRC Sci and Pol Reports, European Comm, Joint Res Centre, Ins for Environ and Sustain. Available at http://publications.jrc.ec.europa.eu/repository/bitstream/111111111/ 31346/1/lbna25466enn.pdf (Accessed July 2019)

EC-JRC (2012b) Life cycle indicators basket-of-products: development of life cycle based macro-level monitoring indicators for resources, products and waste for the EU-27. JRC Tech Report EUR 25518 EN. European Comm. Joint Res Centre. Institute for Environ and Sustain. Available at http://eplca.jrc.ec.europa.eu/uploads/LC-indicators-Basket-of-products.pdf (Accessed July 2019)

EC-JRC (2017) Product Bureau. Available at: http://susproc.jrc.ec. europa.eu/product_bureau/projects.html (Accessed September 2018)

EC-JRC (2018) Environmental Footprint reference package 3.0 (EF 3.0). Available at: https://eplca.jrc.ec.europa.eu/LCDN/developerEF. xhtml (Accessed July 2019)

EC-JRC (2021). Consumption footprint. https://eplca.jrc.ec.europa.eu/ sustainableConsumption.html (Accessed July 2021)

EEA (2019) The European environment - state and outlook 2020. Knowledge for transition to a sustainable Europe. Luxembourg: Pub Office of the European Union. ISBN 978-92-9480-090-9, doi:https://doi.org/10.2800/96749.

Eurostat (2019a) Statistics on International trade detailed data (EU trade since 1995 by HS6 - DS-016893). Available at https://ec.europa.eu/ eurostat/web/international-trade-in-goods/data/database (Accessed May 2019)

Eurostat (2019b) Statistics on the production of manufactured goods (Dataset DS-066341, reference year 2010 and 2015). Available at http://ec.europa.eu/eurostat/web/prodcom/data/database (Accessed May 2019)

Fazio S, Biganzoli F, De Laurentiis V, Zampori L, Sala S, Diaconu E (2018) Supporting information to the characterisation factors of recommended EF Life Cycle Impact Assessment methods, version 2, from ILCD to EF 3.0, EUR 29600 EN, Pub Office of the European Union, Luxembourg

Font Vivanco D, Sala S, McDowall W (2018) Roadmap to rebound: how to address rebound effects from resource efficiency policy. Sustain 10(6):2009
Hischier R, Reale F, Castellani V, Sala S (2020) Environmental impacts of household appliances in Europe and scenarios for their impact reduction, J Clean Prod, 267, 121952

Ivanova D, Stadler K, Steen-Olsen K, Wood R, Vita G, Tukker A, Hertwich EG (2016) Environmental impact assessment of household consumption. J Ind Ecol 20(3):526-536

Kabir ER, Rahman MS, Rahman I (2015) A review on endocrine disruptors and their possible impacts on human health. Environ Toxicol Pharmacol 40(1):241-258

Kalbar PP, Birkved M, Kabins S, Nygaard SE (2016) Personal metabolism (PM) coupled with life cycle assessment (LCA) model: Danish case study. Environ Int 91:168-179

Lavagna M, Baldassari C, Campioli A, Giorgi S, Dalla Valle A, Castellani V, Sala S (2018) Benchmarks for environmental impact of housing in Europe: definition of archetypes and LCA of the residential building stock. Build Environ 145:260-275

Liobikiene G, Dagiliute R (2016) The relationship between economic and carbon footprint changes in EU: the achievements of the EU sustainable consumption and production policy implementation. Environ Sci and Pol 61(2016):204-211. https://doi.org/10. 1016/j.envsci.2016.04.017

Notarnicola B, Tassielli G, Renzulli PA, Castellani V, Sala S (2017) Environmental impact of food consumption in Europe. J Clean Prod 140(2):753-765

Phillips K, Yau AY, Favela KA, Isaacs KK, McEachran A, Grulke CM, Richard AM, Williams A, Sobus JR, Thomas RS, Wambaugh JF (2018) Suspect screening analysis of chemicals in consumer products. Environ Sci Technol 52(5):3125-3135

Pourzahedi L, Vance M, Eckelman MJ (2017) Life cycle assessment and release studies for 15 nanosilver-enabled consumer products: investigating hotspots and patterns of contribution. Environ Sci Technol 51(12):7148-7158

Reale F, Castellani V, Hischier R, Corrado S, Sala S (2019) Consumer footprint - basket of products indicator on household appliances Publications Office of the European Union European Commission, Joint Research Centre, Luxembourg 978-92-76-05003-2, https:// doi.org/10.2760/964701

Rudel RA, Camann DE, Spengler JD, Korn LR, Brody JG (2003) Phthalates, alkylphenols, pesticides, polybrominated diphenyl ethers, and other endocrine-disrupting compounds in indoor air and dust. Environ Sci Technol 37(20):4543-4553

Sala S, Castellani V (2019) The consumer footprint: monitoring sustainable development goal 12 with process-based life cycle assessment. J Clean Prod 240:118050. https://doi.org/10.1016/j.jclepro. 2019.118050

Sala S, Cerutti AK, Pant R (2018) Development of a weighting approach for the environmental footprint Publications Office of the European Union Luxembourg 978-92-79- 68042-7

Sandin G, Roos S, Spak B, Zamani B, Peters G (2019) Environmental assessment of Swedish clothing consumption. Mistra Future Fashion report number 5. ISBN:978-91-89049-05-5

Sanyé-Mengual E, Secchi M, Corrado S, Beylot A, Sala S (2019) Assessing the decoupling of economic growth from environmental impacts in the European Union: a consumption-based approach. J Clean Prod, 236, 117535

Ternes TA, Herrmann N, Bonerz M, Knacker T, Siegrist H, Joss A (2004) A rapid method to measure the solid-water distribution coefficient $(\mathrm{Kd})$ for pharmaceuticals and musk fragrances in sewage sludge. Water Res 38(19):4075-4084

Teubler J, Buhl J, Lettenmeier M, Greiff K, Liedtke C (2018) A household's burden-the embodied resource use of household equipment in Germany. Ecol Econ 146:96-105

Tukker A, Cohen MJ, Hubacek K, Mont O (2010) The impacts of household consumption and options for change. J Ind Ecol 14(1):13-30 
UN (United Nations) (2015) Sustainable Development Goals. Available at https://sustainabledevelopment.un.org/

Vanderheyden G, Aerts J (2014) Comparative LCA assessment of Fontinet filtered tap water vs. natural sourced water in a PET bottle. Available at: https://myfontinet.com/xx_website_sale/static/src/ pdf/MyFontinet_Footprint_LCA_report_milieu16.pdf (Accessed May 2017)

Vojta Š, Bečanová J, Melymuk L, Komprdová K, Kohoutek J, Kukučka P, Klánová J (2017) Screening for halogenated flame retardants in European consumer products, building materials and wastes. Chemo 168:457-466

Wernet G, Bauer C, Steubing B, Reinhard J, Moreno-Ruiz E, Weidema B (2016) The ecoinvent database version 3 (part I): overview and methodology. The Int J Life Cycle Assess 21(9):1218-1230
Wood R, Moran D, Stadler K, Ivanova D, Steen-Olsen K, Tisserant A, Hertwich EG (2017) Prioritizing consumption-based carbon policy based on the evaluation of mitigation potential using inputoutput methods. J Ind Ecol. https://doi.org/10.1111/jiec.12702

Zampori L, Pant R (2019) Suggestions for updating the Product Environmental Footprint (PEF) method, EUR 29682 EN. Publications Office of the European Union, Luxembourg

Zhu Q, Peng X, Wu K (2012) Calculation and decomposition of indirect carbon emissions from residential consumption in China based on the input-output model. Energy Policy 48:618-626

Publisher's Note Springer Nature remains neutral with regard to jurisdictional claims in published maps and institutional affiliations. 